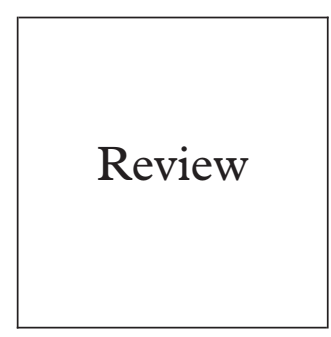

\section{Pathogenesis of chlamydia induced pelvic inflammatory disease}

\author{
Craig R Cohen, Robert C Brunham
}

Department of

Obstetrics and

Gynecology, University of Washington, Seattle, USA

C R Cohen

Department of Medical Microbiology, University of Manitoba, Winnipeg, Canada

R C Brunham

Correspondence to: Dr Craig R Cohen, Department of Obstetrics and Gynecology, University of Washington, Box 356460, Seattle, WA 98103-6460, USA.

Accepted for publication 21 December 1998

\section{Introduction}

Chlamydia trachomatis is the most common cause of pelvic inflammatory disease (PID) in the United States, ${ }^{1}$ and is an important cause of female infertility worldwide. ${ }^{23}$ Our understanding of the immunopathological pathways associated with genital $C$ trachomatis infection and reproductive sequelae such as tubal infertility and ectopic pregnancy remains incomplete. Current observations show that only a fraction of women infected with $C$ trachomatis develop upper genital tract infection, and only a subset of those women develop tubal infertility. Studies in macaques have shown that a single episode of chlamydia salpingitis is usually self limiting, whereas repeated infection eventually produces severe tubal scarring. These and other findings suggest that acquired immune responses to chlamydial antigens are important in pathogenesis. ${ }^{4}$ Other research has suggested that genetic and immunological risk factors are associated with risk of salpingitis ${ }^{5}$ and subsequent tubal damage. ${ }^{67}$ In addition, Dean et al reported that specific major outer membrane protein (MOMP) variants are associated with upper genital tract infection. ${ }^{8}$ Thus both bacterial and host factors appear to influence the pathogenesis of chlamydial disease.

The development of tubal scarring secondary to $C$ trachomatis ultimately depends upon initial infection of the female lower genital tract, usually the cervix. ${ }^{9}$ Once lower genital tract infection occurs, the infection must ascend via the endometrial cavity to the endosalpinx in order to cause salpingitis and finally tubal scarring. Compartmental models are useful to describe the pathogenesis of chlamydia induced infertility since each step in the causal pathway may be associated with distinct genetic, immunological, and bacterial virulence factors. In this review we will elaborate on the pathogenesis of $C$ trachomatis associated PID, and consider host and bacterial factors associated with chlamydial disease pathogenesis.

\section{Epidemiological risk factors for $C$} trachomatis pelvic inflammatory disease Several epidemiological factors have been studied with regard to risk of chlamydia associated PID. ${ }^{10}$ Repeated $C$ trachomatis infection has been associated with both an increased risk of PID and infertility, and supports the hypothesis of immune mediated chlamydial induced pathogenesis. Oral contraceptives appear to increase the risk of acquiring cervical $C$ trachomatis infection, decrease the risk of PID, and have no effect on the risk of tubal factor infertility. ${ }^{511}$ The mechanism by which contraceptive steroids confer protection from acquiring symptomatic chlamydial PID is unknown and deserves further research. HIV-1 infection has been associated with an increased incidence of $C$ trachomatis infection, and increased risk of PID among CD4 T cell deficient HIV-1 infected women. ${ }^{512}$

\section{Chlamydial heat shock protein-60}

A gradient in seroprevalence to chlamydial heat shock protein-60 (Chsp60) has been observed among women with different clinical manifestations of chlamydial infection. Data show that $16 \%-25 \%$ of fertile microimmunofluorescent (micro-IF) antibody positive women have antibody to Chsp60, in comparison with $36 \%$ $44 \%$ of women with $C$ trachomatis cervicitis, $48 \%-60 \%$ of women with chlamydial PID, and $81 \%-90 \%$ of women with $C$ trachomatis associated fallopian tube damage. ${ }^{16}{ }^{13-15}$ Probably the strongest epidemiological evidence is a study of 280 female sex workers prospectively evaluated for incident $C$ trachomatis cervical infection and PID. Among women infected with $C$ trachomatis, those with antibody to Chsp60 had a twofold to threefold increased risk of PID. ${ }^{16}$ In a study using pigtailed macaques, purified recombinant Chsp60 was injected into subcutaneous salpingeal transplants in animals previously sensitised by infection with live $C$ trachomatis organisms. In this experiment, delayed type hypersensitivity reaction in the salpingeal tissue was observed, characterised by mononuclear cell infiltration with a peak reaction at 48 hours $^{17}$; while animals not sensitised by prior $C$ trachomatis infection were unaffected by injection of purified Chsp60. This study provided additional evidence to support the role of Chsp60 in the immunopathogenesis of chlamydial disease.

Chsp60 has important immunological characteristics. The protein is highly conserved in amino acid sequence; chlamydial and human sequences are $48 \%$ homologous. Antibody responses to the Chsp60 protein are genetically determined and in part have been mapped to the MHC locus in mice. ${ }^{18}$ Chsp60 immune recognition may incite an autoimmune inflammatory response through molecular mimicry. ${ }^{19}$ In murine experiments, data showed that an autoimmune response characterised by $\mathrm{T}$ cell proliferation and high titres to mouse hsp60 were preferentially induced only by coimmunisation with mouse and chlamydial hsp60. ${ }^{20}$ These and recent results in humans suggest that an autoimmune response to self hsp60 commonly develops following $C$ trachomatis 
upper genital tract infection, and may be the consequence of an immune response cross reactive to self hsp60 and Chsp60. ${ }^{21}$ Autoimmune inflammation may sustain tissue damage as chlamydial growth becomes inhibited by the acquired immune response.

\section{Genetic factors}

HLA class I molecules present peptides to CD8 $\mathrm{T}$ lymphocytes, and thereby restrict cytotoxic CD8 $\mathrm{T}$ lymphocyte (CTL) responses. HLA class II molecules present peptides to CD4 $\mathrm{T}$ cells and restrict a range of cellular and antibody responses. ${ }^{22}$ Early data support the theory that genetic and immunological risk factors are associated with risk of chlamydial salpingitis, ${ }^{5}$ and subsequent tubal damage. ${ }^{23}$ HLA-A31 was associated with an increased risk of clinical PID among women with $C$ trachomatis infection. ${ }^{5}$ Similarly, HLA class I alleles were associated with susceptibility and resistance to peritubal adhesion formation in pigtailed macaques with experimental $C$ trachomatis salpingeal infection. ${ }^{7}$ In a Gambian population with endemic ocular $C$ trachomatis infection, HLA $A^{\star} 6802$ was associated with an increased risk of trachoma. ${ }^{24}$ Interestingly, while MHC class I restriction of the immune response to $C$ trachomatis is supported by these investigations, HLA class II alleles were not found associated with disease outcome. ${ }^{524}$

In vitro studies of peripheral blood mononuclear cells from patients with and without trachoma suggest that CD4 $\mathrm{T}$ cells which preferentially express Th- 2 cytokines may play a role in the pathogenesis of trachomatous scarring and may be associated with HLA-DQ regulation of the Th1/Th2 response. ${ }^{23}$ We recently studied women with tubal factor infertility in Nairobi, Kenya to investigate genetic factors associated with altered susceptibility to $C$ trachomatis infection as defined by the presence of $C$ trachomatis micro-IF antibody, and tubal factor infertility (CR Cohen et al, unpublished data). Ninety three women were HLA class II genotyped-47 women with tubal factor infertility and 46 women undergoing tubal ligation serving as controls. DQA ${ }^{\star} 0102$ was associated with resistance and $\mathrm{DQB}^{\star} 0501$ was associated with an increased prevalence of $C$ trachomatis micro-IF antibody. HLA class II alleles were not strongly correlated with additional increased risk of tubal infertility among $C$ trachomatis seropositive women (table 1 ). Thus these data may suggest that susceptibility to $C$ trachomatis infection may be HLA class II restricted. As an alternative explanation, these HLA class II alleles may be in linkage disequilibrium with an unstudied gene which itself causes the altered risk of $C$ trachomatis infection. Because of multiple comparisons, this study, as well as other epidemiological studies referenced in this section, probably overrepresents the extent of genetic associations with chlamydial infection and disease pathogenesis. Population based studies that focus on specific alleles will be required to verify these relations.
Table 1 Association of selected HLA class II alleles with risk of $C$ trachomatis micro-IF seropositivity among a weighted sample of women in Nairobi, Kenya (CR Cohen et al, unpublished data)

\begin{tabular}{ll}
\hline HLA class II allele & Weighted sample \\
\hline $\mathrm{DQA}^{\star} 0101$ & $\mathrm{OR}=1.7(0.6-4.4)$ \\
$\mathrm{DQA}^{\star} 0102$ & $\mathrm{OR}=0.4(0.1-0.8)$ \\
$\mathrm{DQA}^{\star} 0501$ & $\mathrm{OR}=2.2(1.0-5.1)$
\end{tabular}

*Weighted multivariate model adjusting for lifetime number of sex partners assuming $15 \%$ prevalence of tubal factor infertility in reproductive aged women in Nairobi, Kenya.

\section{Humoral immunity to $C$ trachomatis infection}

The $C$ trachomatis immunodominant major outer membrane protein (MOMP) is both a target of neutralising antibodies and a serotyping antigen. Relative resistance occurs towards reinfection with the identical $C$ trachomatis serological variant (serovar). ${ }^{25}$ Wang and Grayston recognised that $C$ trachomatis infection preferentially induces serovar specific micro-IF antibody and that reinfection with a $C$ trachomatis variant different from the original serovar recalled antibodies to the original serovar, a phenomenon termed original antigenic $\sin .{ }^{26}$ Local antibody mediated neutralisation of infectivity seems probable since secretory IgA antibody to $C$ trachomatis in cervical mucus has been inversely correlated with quantitative shedding of the organism in the genital tract, and antibody to MOMP can neutralise the organism in vivo. ${ }^{27}{ }^{28}$ In a murine model using $\beta$ cell deficient mice which do not produce antibody, resistance to $C$ trachomatis infection was only modestly or not impaired in comparison with $\beta$ cell intact mice. ${ }^{29} 30$ Furthermore, women with high micro-IF titres to MOMP $(\geqslant 1: 128)$ were not more likely to develop clinical PID. ${ }^{5}$ Thus, humoral immunity may not be sufficient or an absolute requirement for acquired resistance to $C$ trachomatis infection or chlamydial induced PID. These findings require confirmation in humans.

\section{Cell mediated immunity to $C$ trachomatis infection}

The histopathological response to $C$ trachomatis infection offers insight into the pathogenesis of immune mediated tissue damage. Responses to ocular infection are quite similar to responses seen with genital tract infection. ${ }^{31-34}$ Characteristically, the epithelial surface is damaged with cell loss and vacuolisation often in juxtaposition to intraepithelial lymphocytes. Epithelial cell degeneration occurring in close approximation to lymphocytes has been suggested as the immunological hallmark of tissue destruction due to $C$ trachomatis infection. ${ }^{35}$ Diffuse, dense infiltration with mononuclear cells occurs beneath the epithelium and neutrophil exudation occurs through the epithelium into the lumen. Many $\mathrm{T}$ lymphocytes and fewer plasma cells are found throughout the stroma and within the epithelium. ${ }^{32}$ Fibroblastic activity is increased and collagen is deposited. ${ }^{36}$

Little is known about the human cell mediated immune response to $C$ trachomatis infection, and most of our knowledge is derived 
from animal or in vitro models. $\mathrm{T}$ cells accumulate at the site of infection and play a critical role in controlling the infection. ${ }^{37}$ During reinfection $\mathrm{T}$ cells accumulate more rapidly and in larger numbers compared with primary infection. It has also been suggested that epithelial cells infected with chlamydia may be important at initiating an inflammatory process through the secretion of proinflammatory cytokines such as IL- $1 \alpha$ and IL- $8 .^{38}$

Conflicting evidence in mice supports the role of $\mathrm{CD} 4$ and/or CD8 $\mathrm{T}$ cells in protective immunity to $C$ trachomatis. Using a gene knockout model, one study demonstrated that MHC class II restricted T cell responses were absolutely required for the development of protective immunity to $C$ trachomatis, whereas the MHC class I restricted $\mathrm{T}$ cell pathway was not required. ${ }^{39}$ Yet, other researchers found that $C$ trachomatis elicited a CD8 CTL line from $C$ trachomatis infected animals which, when transferred to uninfected animals, conferred immunity. ${ }^{40}$ This study suggested that CTL or cytokine (IFN- $\gamma$ ) secreting CD8 T lymphocytes may limit the establishment of chlamydia infection. Recent tissue based studies in non-human primates have demonstrated induction of mRNA for IFN- $\gamma$, IL-2, IL-6, and IL-10, but not IL-4 by single and repeated chlamydial infection of salpingeal tissue. ${ }^{4142}$ These findings suggest that Th- 1 cytokines (IFN- $\gamma$ and IL-2) may play a role in enhanced intracellular killing of $C$ trachomatis. In parallel murine experiments, anti-IFN- $\gamma$ antibody treatment resulted in significantly prolonged infection while passive administration of IFN- $\gamma$ to chronically infected nude/nude mice caused resolution of infection in some animals. ${ }^{43}$ CD8 cells predominate in the human endometrium, ${ }^{44}$ and are the dominant infiltrating lymphocyte phenotype during acute and repeated $C$ trachomatis infection in the macaque salpingeal infection model. ${ }^{43} \mathrm{Al}$ though the evidence is stronger for CD4 $\mathrm{T}$ cells, ${ }^{45}$ both CD4 and CD8 $\mathrm{T}$ cell restricted mechanisms are likely to be important in $C$ trachomatis associated immunity and disease, affecting different stages of the pathogenic pathway. In the future, it will be important to ascertain the $\mathrm{T}$ cell mechanisms that regulate immunity versus immunopathology.

\section{Bacterial virulence factors}

Although most of this review has focused on host factors in chlamydial disease pathogenesis, we need to be cognizant that immunopathogenesis is regulated through multiple interactions between the bacteria and the host. Since serovars $\mathrm{F}$ and $\mathrm{E}$ have been associated with an increased and decreased risk of severe upper genital tract infections, respectively, ${ }^{9}$ it is logical to propose that certain chlamydial genotypes elicit different immune responses. To understand HLA restriction of $C$ trachomatis infection and pathogenesis it will be important to determine which antigens bind HLA haplotypes that may confer resistance or increased susceptibility to chlamydial infection and that influence risk of upper genital tract infection and subsequent tubal scarring.

\section{Summary}

Further research is necessary to elucidate the pathogenesis of chlamydial PID. It is hoped that these endeavours will eventually lead to a vaccine to prevent not only chlamydia infection, but also chlamydia associated infertility, ectopic pregnancy, and chronic pelvic pain. In the meantime we need to develop strategies to prevent primary and secondary chlamydia infection and its sequelae. Recently, Scholes et al demonstrated that a population based approach to identify and test women at high risk for cervical $C$ trachomatis infection effectively reduced risk of PID. ${ }^{46}$ Hopefully, through the use of public health measures, we can see similar decreases of chlamydia associated genital tract disease worldwide.

1 Westrom L, Mardh P-A. Acute pelvic inflammatory disease (PID). In: Holmes KK, Mardh PA, Sparling PF, Wiesne PJ, eds. Sexually transmitted diseases. New York: McGraw-Hill, 1990:593-613.

2 Muylder X, Laga M, Tennstedt C, et al. The role of Neisseria gonorrhoeae and Chlamydia trachomatis in pelvic inflammatory disease and its sequelae in Zimbabwe. F Infect Dis 1990;162:501-5.

3 Ville Y, Leruez, Galowaczower E, et al. The role of Chlamydia trachomatis and Neisseria gonorrhoeae in the etiology of ectopic pregnancy in Gabon. Br f Obstet Gynaecol 1991; 98:1260-6.

4 Patton DL, Kuo CC, Wang SP, et al. Chlamydial infection of subcutaneous fimbrial transplants in cynomolgus and rhesus monkeys. F Infect Dis 1987;155:229-35.

5 Kimani J, Maclean IW, Bwayo JJ, et al. Risk factors for Chlamydia trachomatis pelvic inflammatory disease among sex workers in Nairobi, Kenya. F Infect Dis 1996;173:143744

6 Toye B, Laferriere C, Claman P, et al. Association between antibody to the chlamydial heat shock protein and tuba infertility. F Infect Dis 1993;168:1236-40.

7 Lichtenwalner AB, Patton DL, Sweeney C, et al. Evidence of genetic susceptibility to Chlamydia trachomatis-induced pelvic inflammatory disease in the pig-tailed macaque. pelvic inflammatory disease

8 Dean D, Oudens E, Bolan G, et al. Major outer membrane protein variants of Chlamydia trachomatis are associated with severe upper genital tract infections and histopathology in San Francisco. F Infect Dis 1995;172 1013-22.

9 Westrom L, Joesoef R, Reynolds G, et al. Pelvic inflammatory disease and infertility: a cohort of 1,844 women with laparoscopically verified disease and 657 control women with normal laparoscopic findings. Sex Transm Dis 1992;19:185

10 Cates W Jr, Rolfs RT Jr, Aral SO. Sexually transmitted diseases, pelvic inflammatory disease, and infertility: an epidemiologic update. Epidemiol Rev 1990:199-220.

11 Wolner-Hanssen P, Eschenbach DA, Paavonen J, et al. Decreased risk of symptomatic chlamydial pelvic inflammatory disease associated with oral contraceptive use. matory disease associate

12 Brunham RC, Kimani J, Bwayo J, et al. The epidemiology of Chlamydia trachomatis within a sexually transmitted diseases core group. F Infect Dis 1996;173:950-6.

13 Brunham RC, Peeling R, Maclean I, et al. Chlamydia trachomatis-associated ectopic pregnancy: serologic and histologic correlates. F Infect Dis 1992;165:1076-81

14 Stamm WE, Peeling RW, Money D, et al. Prevalence and correlates of antibody to chlamydia hsp-60 in C trachomatis infected women. Presented at Eighth International Symposium on Human Chlamydial Infection, Chantilly, France, June 1994.

15 Eckert LO, Hawes SE, Wolner-Hanssen P, et al. Prevalence and correlates of antibody to chlamydial heat shock protein in women attending sexually transmitted disease clinics in women attending sexually transmitted disease clinics and women with confirmed

16 Peeling RW, Kimani J, Plummer F, et al. Antibody to chlamydial hsp60 predicts an increased risk for chlamydial pelvic inflammatory disease. F Infect Dis 1997;175:1153-8.

17 Patton DL, Sweeney YT, Kuo CC. Demonstration of delayed hypersensitivity in Chlamydia trachomatis salpingitis in monkeys: a pathogenic mechanism of tubal damage. f Infect Dis 1994;169:680-3.

18 Zhong G, Brunham RC. Antibody responses to the chlamydial heat shock proteins hsp60 and hsp70 are H-2 linked. Infect Immun 1992;60:3143-9.

19 Lin RH, Mamula MJ, Hardin JA, et al. Induction of autoreactive $B$ cells allows priming of autoreactive $\mathrm{T}$ cells. $\mathcal{f}$ Exp Med 1991;173:1433.

20 Yi Y, Yang X, Brunham RC. Autoimmunity to heat shock protein 60 and antigen-specific production of interleukin10. Infect Immun 1997;65:1669-74 
21 Domeika M, Domeika K, Paavonen J, et al. Humoral immune response to conserved epitopes of Chlamydia trachomatis and human $60-\mathrm{kDa}$ heat-shock protein in women with pelvic inflammatory disease. F Infect Dis 1998;177: 714-9.

22 Janeaway CA, Travers P, eds. Immunobiology: the immune system in health and disease. New York: Garland Publishing, 1997:4:3-20.

23 Holland MJ, Bailey RL, Conway F, et al. T helper type-1 (Th1)/Th2 profiles of peripheral blood mononuclear cells (PBMC); responses to antigens of Chlamydia trachomatis in subjects with severe trachomatous scarring. Clin Exp Immunol 1996;105:429-35.

24 Conway DJ, Holland MJ, Campbell AE, et al. HLA class and II polymorphisms and trachomatous scarring in a Chlamydia trachomatis-endemic population. $\mathcal{F}$ Infect Dis Chlamydia trach

25 Jawetz E, Rose L, Hanna L, Thygeson P. Experimental inclusion conjunctivitis in man. $\mathscr{f} A M A$ 1965;194:150-62.

26 Wang S, Grayston JT. Local and systemic antibody response to trachoma eye infection in monkeys. In: Trachoma and related disorders caused by chlamydial agents. Excerpta Medica Int Congress Series 1971;223;217-32.

27 Brunham RC, Kuo CC, Cles L, et al. Correlation of host immune response with quantitative recovery of Chlamydia trachomatis from the human endocervix. Infect Immun 1983;39:1491-4.

28 Williams DM, Grubbs BG, Pack E, et al. Humoral and cellular immunity in secondary infection due to murine lular immunity in secondary infection due to murine

29 Johansson $M$, Ward $M$, Lycke $N$. $\beta$-cell-deficient mice develop complete immune protection against genital tract infection with Chlamydia trachomatis. Immunology 1997; 92:422-8.

30 Zhang YX, Stewart S, Joseph T, et al. Protective monoclonal antibodies recognize epitopes located on the major oute membrane protein of Chlamydia trachomatis. F Immunol 1987;138:575-81

31 Hare MJ, Toone E, Taylor-Robinson D, et al. Follicular cervicitis-colposcopic appearances and associations with Chlamydia trachomatis. Br f Obstet Gynecol 1981;88:174 80.

32 Kiviat NB, Wolner-Hanssen P, Eschenbach DA, et al. Endometrial histopathology in patient with culture-proved upper genital tract infection and laparoscopically diagnosed acute salpingitis. Am ₹ Surg Pathol 1990;14:167-75.

33 Moller BR, Westrom L, Ahrons S, et al. Chlamydia trachomatis infection of the fallopian tubes. Br F Vener Dis 1979; 55:422-8.
34 El-Asrar AMA, ven den Oord JJ, Geboes K, et al. Immunopathology of trachomatous conjuctivitis. $\mathrm{BrF} \mathrm{Oph}$ thamol 1989;73:276-82.

35 Patton DL, Halbert SA, Kuo CC, et al. Host responses to primary Chlamydia trachomatis infection of the fallopian tube in pig-tailed monkeys. Fertil Steril 1983;40:829-40.

36 Patton DL, Askienazy-Elbhar M, Henry-Suchet J, et al. Detection of Chlamydia trachomatis in fallopian tube tissue in women with postinfectious tubal infertility. $A m \mathcal{F}$ Obstet Gynecol 1994;171:95-101.

37 Rank RG, Soderberg LS, Barron AL. Chronic chlamydial genital infection in congenitally athymic nude mice. Infect Immun $1985 ; 48: 847-9$.

38 Rasmussen SJ, Eckmann L, Quayle AJ, et al. Secretion of proinflammatory cytokines by epithelial cells in response to chlamydia infection suggest a central role for epithelial cell in chlamydial pathogenesis. f Clin Invest 1997;99:77-87.

39 Morrison RP, Feilzer K, Tumas DB. Gene knockout mice establish a primary protective role for major histocompatibility complex class II-restricted responses in Chlamydia trachomatis genital tract infection. Infect Immun 1995;63: 4661-8.

40 Starnbach MN, Bevan MJ, Lampe MF. Protective cytotoxic T lymphocytes are induced during murine infection with

41 Van Voorhis WC, Barrett LK, Cossgrove-Sweeney YT, et al. Repeated Chlamydia trachomatis infection of Macaca nemestrina fallopian tubes produces a Th1-like cytokine response associated with fibrosis and scarring. Infect Immun 1997;65:2175-82.

42 Van Voorhis WC, Barrett LK, Cossgrove-Sweeney YT, et al. Analysis of lymphocyte phenotype and cytokine activity in the inflammatory infiltrates of the upper genital tract of female macaques infected with Chlamydia trachomatis. $\mathcal{F}$ Infect Dis 1996:174:647-50.

43 Johansson M, Schon K, Ward M, et al. Studies in knockout mice reveal that anti-chlamydia protection requires $\mathrm{TH} 1$ cells producting IFN-gamma: is this true for human? Scand f Immunol 1997;46:546-52

44 Pace D, Longfellow M, Bulmer JN. Characterization of intraepithelial lymphocytes in human endometrium. $f$ Reprod Fertil 1991;91:165-74.

45 Rank RG, Ramsey KH, Pack EA, et al. Effect of gamma interferon on resolution of murine chlamydial infection. Infect Immun 1992;60:4427-9.

46 Scholes D, Stergachis A, Heidrich FE, et al. Prevention of pelvic inflammatory disease by screening for cervical pelvic inflammatory disease by screening for cervica
chlamydial infection. $N$ Engl f Med 1996;334:1362-6. 